\title{
Foundation Models for Offshore Wind Turbines
}

\author{
Erica Bush ${ }^{*}$ and Lance Manuel ${ }^{\dagger}$ \\ Dept. of Civil, Architectural, and Environmental Engineering, University of Texas, Austin, TX 78712, USA
}

\begin{abstract}
The objective of this study is to investigate what effect the use of alternative models for monopile pile foundations for shallow-water offshore wind turbines has on extreme loads associated with long return periods that are needed during design. We employ a utility-scale 5MW offshore wind turbine model with a 90-meter hub height in stochastic simulations; the turbine is assumed to be sited in 20 meters of water. Selected 20-year wind-wave combinations are employed as we study comparative time histories, power spectra, response statistics, and probability distributions of extreme loads for fixed-base and flexible foundation models. Two alternative flexible foundation models are considered and longterm loads are studied in comparison with the use of a fixed base model. A discussion on the varying dynamics, on short-term response statistics, and on extrapolated long-term loads from limited simulation is presented. It is shown that root-mean-square (RMS) tower loads are higher for the flexible foundation models than for the fixed-based one. This is due to the smaller stiffnesses of these models. Extreme loads are also higher for the flexible foundation models though not to the same degree as the RMS loads. Seastates involving wind speeds close to the rated wind speed control long-term 20 -year loads which can be as much as $15 \%$ higher for the flexible foundation models compared to the fixed-base one.
\end{abstract}

\section{Introduction}

$\mathrm{C}$ haracteristic loads for the design of wind turbines in ultimate limit states are generally established by employing time-domain aeroelastic response simulations. The accuracy of the derived loads depends on the number of simulations and on how realistically the models used to represent the turbine, support structure, and foundation describe the true structural response. One potential shortcoming in modeling foundations relates to their flexibility. A single pile (often referred to as a monopile) is the most common type of foundation used today for offshore wind turbines; the support structure connects to such a pile foundation that extends some depth below the mudline. Here, we consider three possible ways this foundation can be modeled. A fixed-base model is the simplest of the three and involves a rigid connection of the turbine's support structure to the sea bed. This model does not take into consideration the soil profile at the turbine site and it also does not allow for lateral or rocking motion at the mudline. The other two foundation models are flexible and depend on the actual site's soil properties. The apparent fixity (AF) model has a fixed connection that is located a specific depth below the mudline so as to produce an appropriate translation and rotation at the mudline. The distributed springs (DS) model includes the true length of the monopile foundation and replaces layers of the soil with linear elastic springs. Figure 1 illustrates these two flexible foundation models together with the fixed-base model. These models are based largely on work done by Passon $^{1}$; they are also summarized in the study by Jonkman et. $\mathrm{al}^{2}$. In the present study, we carry out stochastic simulations of a $5 \mathrm{MW}$ offshore wind turbine sited in 20 meters of water and we consider each of the three foundation models for critical environmental conditions believed to control long-term tower loads. Results for the fore-aft tower bending moment at the mudline are compared for the three foundation models.

\section{The Wind Turbine Model}

We use a 5MW wind turbine model ${ }^{3}$ developed at the National Renewable Energy Laboratory (NREL) that closely represents utility-scale offshore wind turbines being manufactured today. The turbine is a variable-speed, collective pitch-controlled machine with a maximum rotor speed of $12.1 \mathrm{rpm}$; its rated wind speed is $11.5 \mathrm{~m} / \mathrm{s}$. It

\footnotetext{
*Graduate Research Assistant

${ }^{\dagger}$ Associate Professor
} 
has a hub 90 meters above the mean sea level and a rotor diameter of 126 meters. It is assumed to be sited in 20 meters of water. The support structure and the wind turbine's tower are modeled as a single continuous cylinder with varying diameter and wall thickness. The monopile support structure for the wind turbine tower has an outer diameter of $6 \mathrm{~m}$ and a wall thickness of $6 \mathrm{~cm}$. The turbine tower attached to the support structure tapers linearly upward. At $10 \mathrm{~m}$ above the mean sea level, the tower has an outer diameter of $6 \mathrm{~m}$ and a wall thickness of $2.7 \mathrm{~cm}$; at the top, the tower has an outer diameter of $3.87 \mathrm{~m}$ and a wall thickness of $1.9 \mathrm{~cm}$. The monopile support structure attaches to a monopile foundation of the same dimensions. The foundation extends $36 \mathrm{~m}$ into the seabed. The soil profile at the site under consideration is shown in Fig. 2; this is the same profile used by Passon ${ }^{1}$. In the figure, $\gamma$ refers to the effective weight, $\Phi$ ' refers to the angle of internal friction, and $k$ refers to the initial modulus of the subgrade reaction. The density of steel of which the tower is constructed is taken to be $8,500 \mathrm{~kg} / \mathrm{m}^{3}$, and the modulus of elasticity is taken to be $2.1 \times 10^{5} \mathrm{MN} / \mathrm{m}^{2}$.
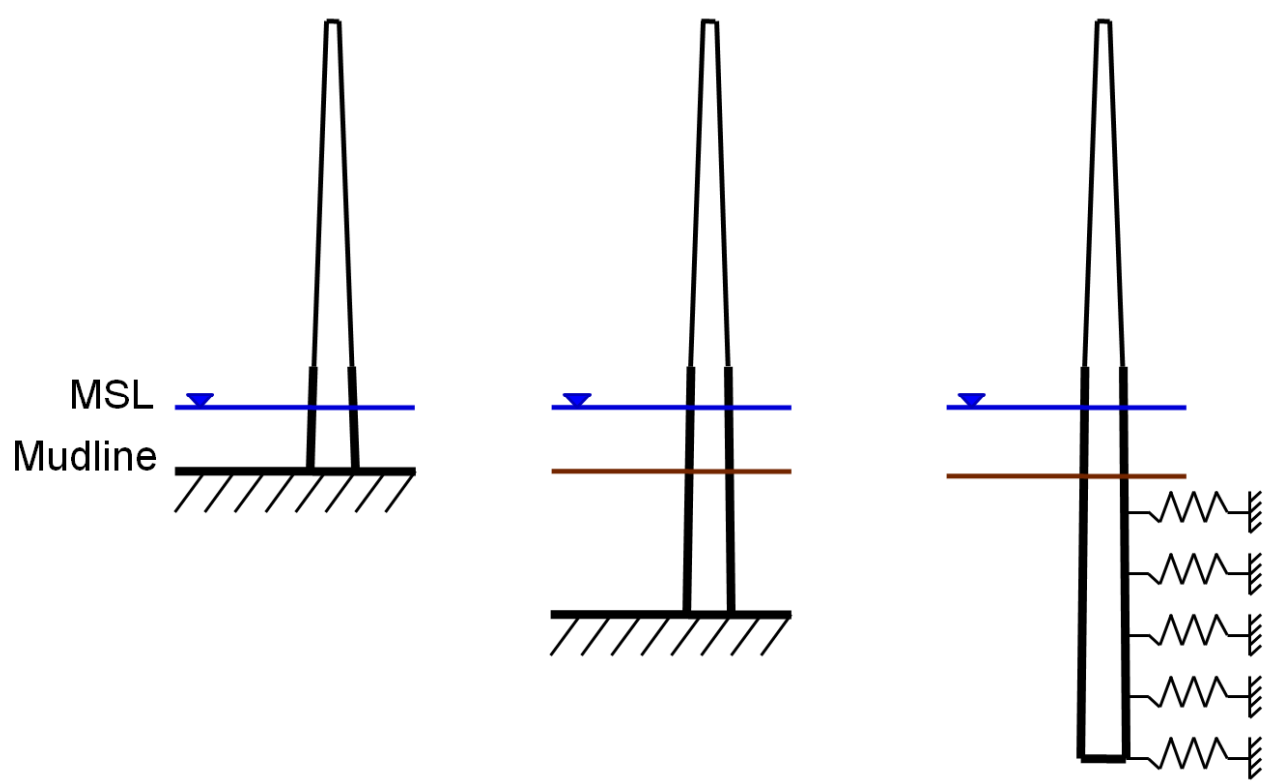

Fixed-Base

Apparent Fixity

Distributed Springs

Figure 1: Alternative foundation models analyzed in this study.

\begin{tabular}{|c|c|c|}
\hline Sand 1 & $\begin{array}{l}\mathrm{Y}=10 \mathrm{kN} / \mathrm{m}^{3} \\
\Phi^{\prime}=33^{\circ} \\
\mathrm{k}=16287 \mathrm{kN} / \mathrm{m}^{3}\end{array}$ & $5 \mathrm{~m}$ \\
\hline Sand 2 & $\begin{array}{l}\mathrm{V}=10 \mathrm{kN} / \mathrm{m}^{3} \\
\Phi^{\prime}=35^{\circ} \\
\mathrm{k}=24430 \mathrm{kN} / \mathrm{m}^{3}\end{array}$ & $9 \mathrm{~m}$ \\
\hline Sand 3 & $\begin{array}{l}\mathrm{y}=10 \mathrm{kN} / \mathrm{m}^{3} \\
\Phi^{\prime}=38.5^{\circ} \\
\mathrm{k}=35288 \mathrm{kN} / \mathrm{m}^{3}\end{array}$ & $22 \mathrm{~m}$ \\
\hline & & , \\
\hline
\end{tabular}

Figure 2: Soil profile at the wind turbine site. 
A Kaimal power spectrum and an exponential coherence spectrum are employed to describe the inflow turbulence random field over the rotor plane, which is simulated using the computer program, TurbSim ${ }^{4}$. For hydrodynamic loading on the support structure, irregular long-crested waves are simulated using a JONSWAP spectrum $^{5}$. The hydrodynamic loads are computed using Morison's equation ${ }^{6}$ and take into account stretching corrections for wave kinematics.

After obtaining time histories of the wind inflow turbulence field from TurbSim, the computer program, $\mathrm{FAST}^{7}$, is used to carry out stochastic time-domain simulations of the turbine response. FAST accounts for aerodynamic loads based on the inflow turbulence input; it also accounts for hydrodynamic loads by first simulating a random sea surface elevation process, and then applying appropriate wave kinematics and inertia and drag force computations using Morison's equation. For the structural response computation, FAST employs a combined modal and multibody dynamics formulation.

\section{Turbine Response Simulations}

We choose here to study the influence of alternative foundation modeling assumptions on extreme wind turbine tower loads by carrying out stochastic response simulations for selected wind-wave environmental conditions. The environmental contour method (2D Inverse $\mathrm{FORM}^{8}$ ) is used to identify candidate seastates, all associated with a 20year return period, from which one is determined to be the critical seastate for the extreme tower load of a fixed-base wind turbine. Table 1 lists two of the environmental contour (EC) seastates that were selected for the present study that investigates tower loads based on alternative foundation models. Two environmental random variables are considered here to represent each seastate; they include the hub-height ten-minute average wind speed, $V$, and the significant wave height, $H_{s}$. The wave spectral peak period, $T_{p}$, is deterministically related to the significant wave height. The Normal Turbulence Model (NTM) ${ }^{9}$ is employed to relate the hub-height turbulence intensity to $V$.

Table 1: Two 20-year return period seastates considered in the wind turbine loads study.

\begin{tabular}{|c|c|}
\hline$V(\mathrm{~m} / \mathrm{s})$ & $H_{s}(\mathrm{~m})$ \\
\hline \hline 12 & 6.2 \\
\hline 22 & 9.0 \\
\hline
\end{tabular}

We are interested in comparing tower loads for the fixed-base model, the apparent fixity (AF) model, and the distributed springs (DS) model. For each sea state, a total of 150 ten-minute turbine response simulations are carried out for the three foundation models. Descriptions of the flexible foundation models are presented next.

\section{Flexible Foundation Models}

\section{A. Apparent Fixity Model}

In the apparent fixity model, the true monopile foundation and the surrounding soil medium are replaced by a cylinder that is fixed not at the original mudline but at a lower depth whose location is derived as a point of apparent fixity for the cantilevered cylinder ${ }^{1,2}$. The associated flexural rigidity of the fictitious pile is derived as well.

The apparent fixity length $(L)$ represents the depth below the mudline where the cantilevered monopile is to be modeled so as to have the same stiffness as the true pile-soil system. Given specified levels of shear $(F)$ and moment $(M)$ at the true mudline, lateral deflections and rotations at the mudline are first determined using the known soil profile, penetration depth, and pile dimensions/properties. This is typically carried out using a pile lateral load analysis program such as LPILE ${ }^{10}$. Note that the axial force in the pile is also needed in order to account for secondary moments (so-called $P-\Delta$ effects) when the pile deflects laterally. However, the shear and moment are of greater importance since deformations are generally small leading to negligible secondary effects as was verified in this study.

Since the nonlinear $p-y$ curves yield different foundation stiffness values (and, thus, different apparent fixity lengths) depending on the applied shear and moment at the mudline, the selected $F$ and $M$ values are important. (The $p-y$ curves for the lateral force-displacement relationships of the selected pile are based on guidelines for offshore platforms provided by the American Petroleum Institute ${ }^{11}$.) In our analyses, we employ typical mudline shear and moment values based on preliminary fixed-base analyses for the selected seastates. For each seastate, 50 contemporaneous $F$ and $M$ pairs are randomly selected from a fixed-base ten-minute simulation. For each of these 
50 force-moment pairs, LPILE is then run to determine the mudline deflection and rotation of the pile and the apparent fixity length and flexural rigidity are calculated.

The length of the equivalent cantilever that will replace the true soil-pile system is that which will produce the same rotation $(\theta)$ and lateral deflection $(w)$ at its free end (the original mudline) under the moment, $M$, and shear, $S$, applied at the mudline. This is referred to as the apparent fixity length $(L)$ and is derived along with the flexural rigidity $(E I)$ of the cantilever using the following equations:

$$
\begin{aligned}
& w=\frac{F L^{3}}{3 E I}+\frac{M L^{2}}{2 E I} \\
& \theta=\frac{F L^{2}}{2 E I}+\frac{M L}{E I}
\end{aligned}
$$

For the two seastates, the apparent fixity length and the flexural rigidity values used in the flexible foundation (AF model) simulations, which are summarized in Table 2, are averages based on all of the $50 F$ and $M$ pairs used.

Table 2: Apparent fixity length and flexural rigidity for the monopile used in the Apparent Fixity foundation model.

\begin{tabular}{||c|c|c||}
\hline \hline$V(\mathrm{~m} / \mathrm{s})$ & $L(\mathrm{~m})$ & $E I\left(\mathrm{MN}-\mathrm{m}^{2}\right)$ \\
\hline \hline 12 & 17.1 & $1.12 \times 10^{6}$ \\
\hline 22 & 15.9 & $1.06 \times 10^{6}$ \\
\hline
\end{tabular}

To model this new fictitious pile in FAST, its length, flexural rigidity, and mass distribution are required. The length and flexural rigidity are determined as described by Eq. (1). The mass distribution (i.e., mass per unit length) is kept the same as that of the monopile above the mudline. While the inertia does not realistically represent the real foundation, inertial effects are assumed negligible because movement of the sub-soil structure is much less than the movement at the top of the tower.

\section{B. Distributed Springs Model}

The distributed springs (DS) model replaces the soil surrounding the pile foundation with discrete springs distributed along the length of the pile. The stiffnesses of these springs depend on the loads at the head of the pile. In deriving the apparent fixity length and stiffness (as discussed for the AF model), fifty contemporaneous shear and moment pairs are randomly selected from a fixed-base wind turbine response simulation for each seastate analyzed. Then, fifty apparent fixity lengths and associated stiffnesses are calculated and the average value is used in the AF model wind turbine response simulations. The DS model requires a single shear and moment pair for each seastate. The pair that is selected from the fifty contemporaneous pairs is the one that produces an apparent fixity length closest to the average value used in the apparent fixity length model. Once representative pile head loads are selected, the associated soil behavior is then calculated. Soil under loading does not behave as a linear elastic material; the more soil is loaded, the softer or less stiff it becomes. The stiffness of the soil under a given load and at a specific depth can be determined from available $p-y$ curves (or load-deflection curves). Each depth has its own associated $p-y$ curve. LPILE is used to analyze the pile in the selected soil profile. The pile head loads (shear and moment) are applied in five thousand cycles of loading. LPILE then computes the load and deflection at 252 points along the length of the embedded pile. The final stiffness associated with each point is taken to be the load divided by the deflection. To minimize the number of springs employed in the DS model, the available computed stiffnesses are condensed down to 37 discrete stiffness values at one-meter spacing along the length of the pile; of the original 252 stiffnesses, those that fall within the tributary length of a discrete spring are added together. Discrete spring stiffnesses that are derived from loads in the horizontal $x$-direction are then applied to the model in both the $x$ and $y$ horizontal directions. 


\section{Numerical Results}

Simulations of the turbine response are performed and the fore-aft tower bending moment at the mudline compared for the three foundation models in the two selected sea states. Mean statistics from the 150 simulations are given in Tables 3 and 4 for mean wind speeds of 12 and $22 \mathrm{~m} / \mathrm{s}$, respectively.

From Tables 3 and 4, one can see that the softer system resulting from use of a flexible foundation model leads to larger RMS levels of response for both seastates. Mean values are only slightly different between the fixed-base and the flexible foundation models. While maximum loads are higher for the flexible foundation models than they are for the fixed-base models, the differences are not as large (proportionately) as they are for the RMS loads; this is because the mean upcrossing rates are smaller for the flexible systems and, hence, peak factors are generally lower for the flexible (AF and DS) models than they are for the fixed-based models. Comparing the two seastates, it can be seen that the maximum loads in Table 3 and somewhat higher despite the smaller wave height for the seastate there; this is mainly due to control actions that limit turbine loads at the higher wind speed of $22 \mathrm{~m} / \mathrm{s}$.

Table 3: Averaged statistics of the fore-aft tower bending moment at the mudline from 150 ten-minute simulations when $V=12 \mathrm{~m} / \mathrm{s}$ and $\mathrm{Hs}=6.2 \mathrm{~m}$.

\begin{tabular}{|c|c|c|c|c|c|c|c||}
\hline \hline \multirow{2}{*}{ Model } & Max & Mean & Std. Dev. & $\begin{array}{c}\text { PF } \\
\text { (on max })\end{array}$ & Skewness & Kurtosis & Mean Upcrossing Rate \\
\cline { 2 - 8 } & $(\mathrm{MN}-\mathrm{m})$ & $(\mathrm{MN}-\mathrm{m})$ & $(\mathrm{MN}-\mathrm{m})$ & - & & & $\left(\mathrm{s}^{-1}\right)$ \\
\hline \hline Fixed-Base & 119.2 & 66.0 & 16.2 & 3.27 & 0.01 & 2.89 & 0.29 \\
\hline AFL & 130.1 & 66.7 & 19.5 & 3.25 & 0.02 & 2.93 & 0.21 \\
\hline DS & 132.6 & 64.5 & 20.1 & 3.38 & 0.03 & 2.91 & 0.26 \\
\hline
\end{tabular}

Table 4: Averaged statistics of the fore-aft tower bending moment at the mudline from 150 ten-minute simulations when $V=22 \mathrm{~m} / \mathrm{s}$ and $\mathrm{Hs}=9.0 \mathrm{~m}$.

\begin{tabular}{|c|c|c|c|c|c|c|c||}
\hline \hline \multirow{2}{*}{ Model } & Max & Mean & Std. Dev. & $\begin{array}{c}\text { PF } \\
\text { (on max })\end{array}$ & Skewness & Kurtosis & Mean Upcrossing Rate \\
\cline { 2 - 8 } & $(\mathrm{MN}-\mathrm{m})$ & $(\mathrm{MN}-\mathrm{m})$ & $(\mathrm{MN}-\mathrm{m})$ & - & & & $\left(\mathrm{s}^{-1}\right)$ \\
\hline \hline Fixed-Base & 105.5 & 34.8 & 18.7 & 3.78 & 0.03 & 3.25 & 0.36 \\
\hline AFL & 112.9 & 35.2 & 23.1 & 3.36 & -0.07 & 3.10 & 0.22 \\
\hline DS & 111.4 & 34.4 & 21.6 & 3.57 & -0.05 & 3.18 & 0.28 \\
\hline \hline
\end{tabular}

Upon studying power spectra of the fore-aft tower bending moment at the mudline in Fig. 3 for the two seastates, it may be confirmed that the flexible foundation models exhibit tower resonance peaks at somewhat lower frequencies than with the fixed-base model.

We next study short-term probability of exceedance plots of the ten-minute extreme fore-aft tower bending moment at the mudline in Fig. 4. Based on the 150 ten-minute simulations for the two selected seastates, it may be seen that, especially for the case when $V$ equals $12 \mathrm{~m} / \mathrm{s}$, differences in the load distributions between the flexible and fixed-base models are large. The two flexible foundation models yield comparable load distributions as can be confirmed from Fig. 4. Note that since the two selected seastates have $V$ and $H_{s}$ values that lie on the 20-year environmental contour, associated median loads from the curves in Fig. 4 may be used as characteristic values in turbine design. It may be seen that these 20 -year characteristic fore-aft tower bending moment values are roughly $128 \mathrm{MN}-\mathrm{m}$ for the fixed-based model and $145 \mathrm{MN}-\mathrm{m}$ for both the flexible foundation models; this suggests about a $15 \%$ increase in the 20 -year load with the flexible foundation models. 


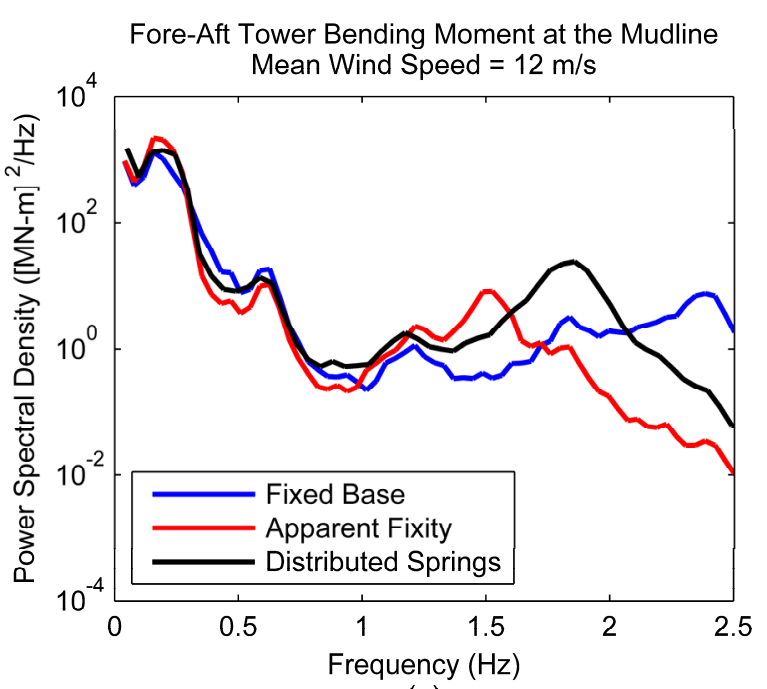

(a)

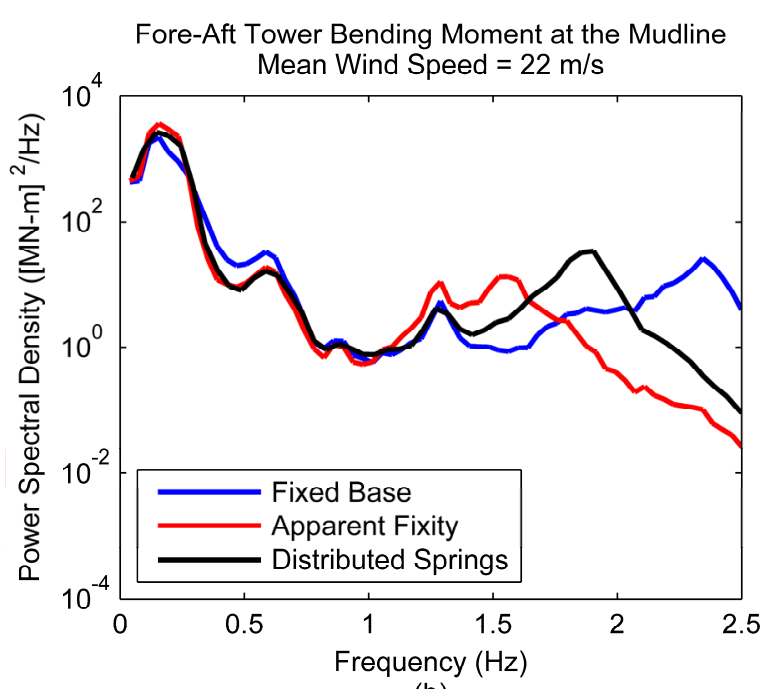

(b)

Figure 3: Power Spectra of the fore-aft bending moment at the mudline for (a) $V=12 \mathrm{~m} / \mathrm{s} ; H_{s}=6.2 \mathrm{~m}$; (b) $V=22 \mathrm{~m} / \mathrm{s} ; H_{s}=9.0 \mathrm{~m}$.

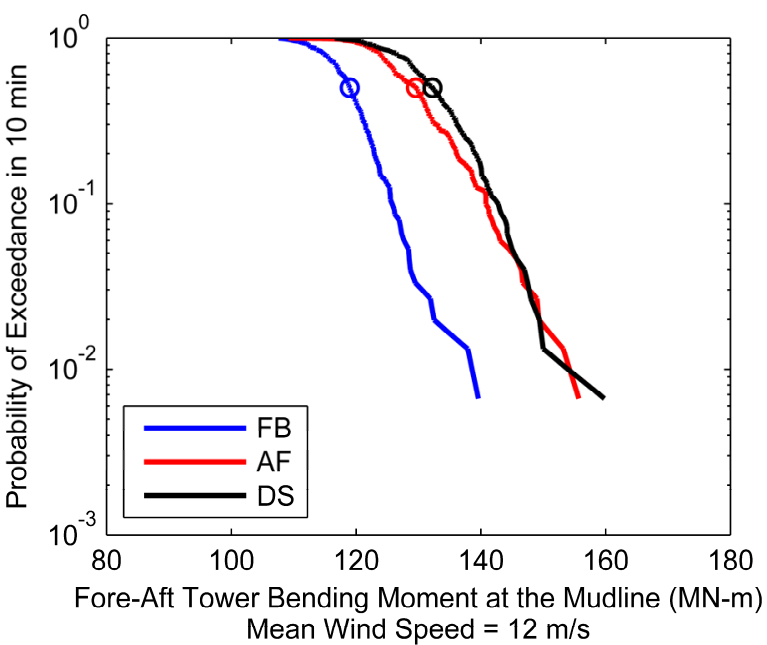

(a)

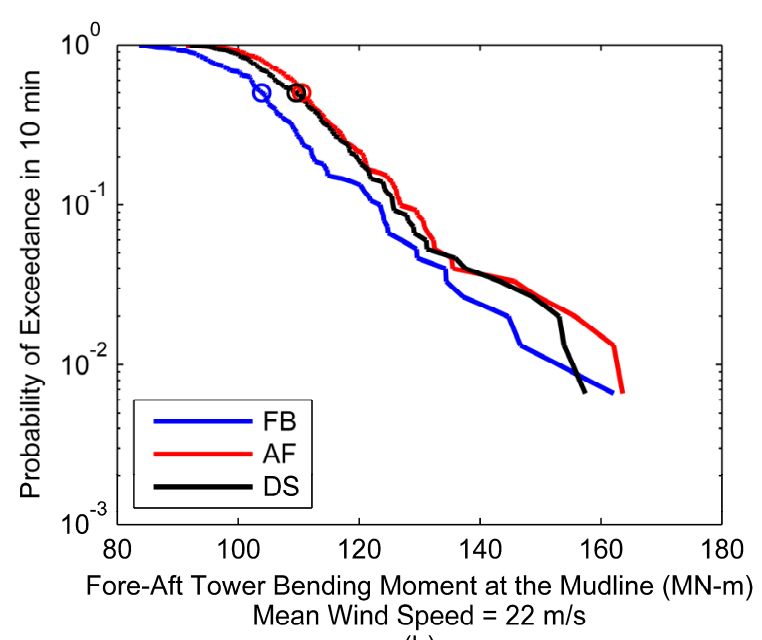

(b)

Figure 4: Probability of exceedance plots of the ten-minute extreme fore-aft bending moment at the mudline for (a) $V=12 \mathrm{~m} / \mathrm{s} ; H_{s}=6.2 \mathrm{~m}$; (b) $V=22 \mathrm{~m} / \mathrm{s} ; H_{s}=9.0 \mathrm{~m}$.

\section{Conclusions}

Fixed-base and flexible foundation models have been employed to study extreme tower loads for an offshore wind turbine. The study is motivated by the need to assess the degree of influence on long-term loads of foundation modeling assumptions. In general, the use of the two flexible foundation models (an apparent fixity model and a distributed springs model) employed here leads to larger long-term extreme loads than for the offshore turbine assumed to be fixed at the mudline. The turbine dynamics are starkly different for the flexible model in that their lower stiffnesses lead to less high-frequency content in the response, higher RMS levels of response, and larger long-term loads. Extreme loads are higher for the flexible foundation models though not to the same degree as the RMS loads. Both the flexible foundation models introduced experience similar long-term tower loads. Seastates involving wind speeds close to the rated wind speed control long-term 20 -year loads which can be as much as $15 \%$ higher for the flexible foundation models compared to the fixed-base one. 


\section{Acknowledgments}

The authors are pleased to acknowledge the financial support received from the National Science Foundation by way of two grants-Award Nos. CMMI-0049128 (CAREER) and CMMI-0727989. They also thank Dr. Jason Jonkman at the National Renewable Energy Laboratory for his continued assistance with the program, FAST, and for the wind turbine simulation model used in this study. Finally, they thank Ensoft, Inc. for providing LPILE for our use and Dr. Shin Tower Wang, in particular, for his assistance with that program

\section{References}

${ }^{1}$ Passon, P., "Memorandum: Derivation and Description of the Soil-Pile-Interaction Models" IEA-Annex XXIIII Subtask 2 , Stuttgart, Germany, 2006.

${ }^{2}$ Jonkman, J., Butterfield, S., Passon, P., Larsen, T., Cap, T., Nichols, J., Azcona, J., and Martinez, A., "Offshore Code Comparison Collaboration within IEA Wind Annex XXIII: Phase II Results Regarding Monopile Foundation Modeling," Proceedings of the IEA European Offshore Wind Conference, Berlin, Germany, 2007.

${ }^{3}$ Jonkman, J. M., Butterfield, S., Musial, W., and Scott, G., "Definition of a 5MW Reference Wind Turbine for Offshore System Development," Tech. Rep. NREL/TP-500-38060, National Renewable Energy Laboratory, Golden, CO, (to be published), 2007.

${ }^{4} J o n k m a n$, B. J. and Buhl, M. L. Jr, “TurbSim User's Guide,” NREL/TP- 500-41136, National Renewable Energy Laboratory, Golden, Colorado, 2007.

${ }^{5}$ DNV-OS-J101, "Design of Offshore Wind Turbine Structures," Offshore Standard, Det Norske Veritas, 2007.

${ }^{6}$ Barltrop, N., and Adams, A., "Dynamics of Fixed Marine Structures," Butterworth-Heinemann, London, 1991.

${ }^{7}$ Jonkman, J. M. and Buhl, M. L. Jr, “FAST User's Guide,” National Renewable Energy Laboratory, NREL/EL-500-38230, Golden, CO, 2005.

${ }^{8}$ Wintersteinn, S. R., Ude, T. C., Cornell, C. A., Bjerager, P., and Haver, S., "Environmental Contours for Extreme Response: Inverse FORM with Omission Factors," Proc. ICOSSAR-93, Innsbruck, 1993.

9International Electrotechnical Commission, "IEC 61400-1: Wind Turbines - Part 1: Design Requirements," Edition 3, 2005.

${ }^{10}$ Reese, L. C., Wang, S. T., Isenhower, W. M., Arréllaga, J. A., and Hendrix, J., 2004, "Computer Program LPILE Plus Version 5.0 User's Guide: A Program for the Analysis of Piles and Drilled Shafts Under Lateral Loads," Ensoft, Inc., Austin, TX.

${ }^{11}$ API RP 2A-WSD, 2000, "Recommended Practice for Planning, Designing and Constructing Fixed Offshore PlatformsWorking Stress Design,” 21st Edition. 